\title{
PROPOSTA DA FERRAMENTA 5W2H NA GESTÃO DE LOGÍSTICA: ESTUDO DE CASO NA INSTITUIÇÃO CASA DE APOIO CORAÇÃO DE MÃE
}

\section{ARTIGO ORIGINAL}

ALVES, Helen Stéfane Corrêa ${ }^{1}$

ALVES, Berg Alesy Nascimento ${ }^{2}$

BARBOSA, Jorgelina Nascimento ${ }^{3}$

ROBERTO, José Carlos Alves ${ }^{4}$

ALVES, Helen Stéfane Corrêa. Et al. Proposta da Ferramenta 5W2H na Gestão de Logística: Estudo de caso na Instituição Casa de Apoio Coração de Mãe. Revista Científica Multidisciplinar Núcleo do Conhecimento. Ano 05, Ed. 11, Vol. 05, pp. 3452. Novembro de $2020 . \quad$ ISSN: 2448-0959, Link de acesso: https://www.nucleodoconhecimento.com.br/administracao/proposta-daferramenta

\section{RESUMO}

O presente artigo tem como finalidade apresentar uma proposta de solução que surgiu a partir da realização do Diagnóstico Organizacional na Instituição de Borba - Casa de Apoio Coração de Mãe, localizada na cidade de Manaus. Além disso, como objetivo geral, buscou-se organizar um plano estratégico a partir da ferramenta $5 \mathrm{~W} 2 \mathrm{H}$,

${ }^{1}$ Graduanda em Administração.

2 Graduanda em Administração.

${ }^{3}$ Graduanda em Administração.

${ }^{4}$ Orientador. Mestrado profissional em Engenharia de produção. Especialização em Gestão em Logística empresarial. Graduação em Administração com Ênfase em Marketing. 
baseada no diagnóstico de logística da instituição, direcionando as atividades como forma de maximizar os resultados operacionais da mesma. Para fundamentar este artigo, foram apresentados conceitos sobre a administração descrevendo suas perspectivas, a logística enfatizando a sua importância, o processo logístico e a administração de materiais. Esta pesquisa teve como base uma pesquisa bibliográfica, com abordagem mista ou quali-quantitativa, quanto aos fins foi exploratória, e em relação aos meios, esta foi baseada em uma pesquisa de campo. A partir da análise dos dados da pesquisa, a equipe obteve uma visão mais clara do que realmente é necessário para melhorar o processo logístico da instituição proposta no estudo.

Palavras-Chaves: Logística, estratégia, intervenção, organizacional.

\section{INTRODUÇÃO}

A proposta de solução para esse estudo de caso, surgiu a partir da realização do Diagnóstico Organizacional na Instituição de Borba - Casa de Apoio Coração de Mãe, do qual desempenha serviços comunitários de acolhimento aos cidadãos nascidos em Borba/AM e seus respectivos acompanhantes, que buscam atendimento de saúde na cidade de Manaus.

Através do diagnóstico realizado a equipe constatou que a instituição proposta no estudo, apresenta falhas ou deficiência no processo logístico por conta de não haver tal processo ou um departamento logístico específico para tal função.

Com isso, houve a inevitabilidade de propor uma ferramenta estratégica para melhoria da instituição em otimizar os seus processos. Haja vista, que a logística está presente em toda parte, e se faz necessário por ser determinante para o êxito da instituição diante da concorrência, em razão da mesma envolver toda a cadeia, facilitar e auxiliar a atividade de fluxo de informações, capitais e materiais, abrangendo todo o processo de fabricação até o consumidor final. 
A verdade é que os concorrentes surgem a toda hora e, se o empresário deseja manter o negócio ativo e com visibilidade, precisa inovar e se diferenciar. Com o crescimento das empresas, surgem novos concorrentes, é importante que o empresário busque inovar, pois assim permitirá que a empresa se mantenha competitiva no mercado (CUSTÓDIO, 2011).

A partir desse contexto, o objetivo geral do estudo é organizar um plano estratégico a partir da ferramenta $5 \mathrm{~W} 2 \mathrm{H}$, baseada no diagnóstico de logística da instituição estudada, direcionando as atividades como forma de maximizar seus resultados operacionais. Como objetivos específicos foram estabelecidos: llustrar a importância da logística aplicados a gestão; analisar as principais dificuldades encontradas na estratégia de logística da instituição estudada; criar um plano de logística adequado a realidade competitiva da instituição.

Desta forma, este estudo justifica-se pelo fato da logística ter o potencial de agregar valores e integrar os recursos, maximizando os resultados, tanto na visão dos pacientes, pois este adquire produtos com maior valor agregado, quanto na visão da instituição, que consegue explorar novas oportunidades de mercado a partir da eficiência logística.

Este estudo será oferecido como subsídio para a comunidade acadêmica aprimorar conhecimentos sobre o assunto, incentivando estudos sobre as novas necessidades e tendências do mercado. Além de proporcionar maiores conhecimentos para a formação profissional dos autores.

\section{REVISÃO BIBLIOGRÁFICA}

A revisão bibliográfica trata-se de uma análise profunda realizada em publicações correspondentes a uma determinada área de estudo, objetivando a busca por respostas ou maiores conhecimentos sobre um determinado assunto. De acordo com Santos (2018) uma boa revisão bibliográfica impulsionará a pesquisa. Para proporcionar o avanço em um campo do conhecimento é preciso primeiro conhecer o 
que já foi realizado por outros pesquisadores e quais são as fronteiras do conhecimento naquela.

A revisão bibliográfica possibilita a ascensão de vários estudos de revisão em diferentes áreas do conhecimento, de modo a manter o rigor metodológico das revisões sistemáticas.

Essa metodologia consente na combinação de dados da literatura empírica e teórica que podem conduzir definições de conceitos, identificação de lacunas nas áreas de estudos, revisões de teorias e a análise metodológica de várias vertentes de um determinado tópico (MATTOS et al., 2015).

\subsection{ADMINISTRAÇÃO E SUAS PERSPECTIVAS}

Atualmente, a administração apresenta-se como uma área do conhecimento humano repleta de complexidades e desafios.

"O profissional que utiliza a administração como meio de vida pode atuar nos mais variados níveis de uma organização, desde o hierárquico de supervisão elementar até o de dirigente máximo da organização" (CHIAVENATO, 2014, p. 8).

"Pode atuar nas diversas especializações da administração: da produção de bens ou serviços prestados pela organização, financeira, de recursos humanos, mercadológica ou, ainda, administração geral” (CHIAVENATO, 2014, p. 8).

Destaca-se que cada organização é única e possui seus próprios objetivos, ramo de atividade, dirigentes e pessoal, problemas internos e externos, mercado, situação financeira, tecnologia, recursos básicos, ideologia e política de negócios, entre outros (CHIAVENATO, 2014).

Sobre a temática, Rocha, (2015, p. 20), explica que o profissional de administração deve "definir estratégias, traça metas, liderar equipes, elaborar políticas internas, avaliar resultados, fazer o relacionamento com clientes e fornecedores, buscando soluções que garantam um gerenciamento eficiente." 
Apresentando uma perspectiva diferente, Ribeiro (2016), explica que a administração apresentou diferentes enfoques e visões ao longo do tempo. No entanto, apesar dos diferentes tratamentos atribuídos a ela, a mesma continua a assumir a forma de aprimorar os meios, a fim de atingir os melhores fins.

Neste sentido, conclui-se que é de extrema importância o administrador buscar o aperfeiçoamento de suas habilidades e a concretização de uma base sólida especializada, para assim facilitar a condução dos esforços organizacionais na conquista dos seus objetivos, e consequentemente mantendo-se competitivo e com vida longa no mercado atuante.

\subsection{LOGÍSTICA}

A logística hoje, é uma ferramenta importante para as empresas à medida que otimiza recursos e aumenta a qualidade, o que significa, gastar menos com resultados melhores.

Segundo Vitorino (2012), a palavra "logística", está na moda, volta e meia ela aparece nos noticiários e ambientes de trabalho.

Nessa linha de raciocínio, Castiglioni; Junior (2014), entende que a empresa por meio de seus projetos logísticos perante sua administração deve se comportar a fim de buscar lucro diante desses processos logísticos.

O foco da logística consiste em fazer com os recursos cheguem na quantidade certa, no tempo certo, no lugar certo e pelo melhor preço (CASTIGLIONI; JUNIOR, 2014).

Segundo Marques; Oda, (2012, p. 17), "a busca pela qualidade pode, às vezes, soar estranho para quem tem como um dos objetivos a redução de custos".

Atualmente, a logística tem sido um fator estratégico para as empresas, uma vez que ela trata de processos que envolvem a redução de custo e, às vezes, de investimentos. 
Sendo assim, é possível concluir que a logística ajuda não somente as instituições, mas a qualidade de vida local, no que diz respeito ao desenvolvimento de infraestrutura para sua operacionalidade. Por essa razão, a forma como uma instituição gerencia sua cadeia de suprimentos pode ser decisiva para sua sobrevivência.

\subsection{A IMPORTÂNCIA DA LOGÍSTICA}

Nos dias de hoje, verifica-se que, sob a perspectiva de um mundo altamente competitivo, empresas de diferentes portes e segmentos precisam sobreviver, encarando os desafios da globalização dos mercados, impactados sobretudo pelas incertezas sazonais do cambio e as exigências dos padrões de qualidade de produtos sendo eles nacional e internacional.

A logística vem ganhando mais importância a cada dia nas relações comerciais e é imprescindível na estruturação das bases para o planejamento estratégico de uma empresa.

Como ponto de partida, Vitorino, (2012, p. 4), entende que é extremamente importante que "as empresas estejam antenadas para atender às expectativas dos seus clientes e com isso conquistar seu espaço no mercado através de produtos e serviços de qualidade, cumprindo seus prazos e aumentando suas margens de lucro."

Isso exige das empresas habilidade, agilidade, boas performances e constância na procura por redução de custos.

Sob o cenário atual, constou-se que a demanda tem-se variado, enquanto as previsões tornaram-se cada vez menos confiáveis, ao ponto de necessitar de novas previsões, visto que antecipar-se as mudanças é um fator essencial para reagir com maior rapidez.

Assim, para que as empresas sobrevivam as pressões internas e externas, elas devem apresentar competências gerenciais e técnicas que proporcionem resultados 
sobre os quesitos de quantidade, variedade, qualidade, preços e prazos, de acordo com as necessidades e expectativas dos clientes, cada vez mais exigentes.

Com base no texto acima, as lições de Silva, (2015) explicam que há a necessidade da realização de um bom trabalho sobre as operações logísticas, para que os custos sejam reduzidos e a empresa consiga obter vantagens e benefícios.

Em função disso, identificamos que os estoques dos insumos e dos produtos acabados, a infraestrutura de transporte e a aptidão da gerência logística são fatores cruciais para a atuação das organizações e o sucesso no desempenho das operações logísticas.

A logística moderna é a estratégia fundamental para as instituições enfrentarem a competitividade em ambientes de mudanças turbulentas.

Portanto, entende-se que é preciso adotar ferramentas e métodos racionais em cada etapa, determinando o que produzir e, ainda, como e quanto produzir, bem como a maneira de como cuidar dos estoques e distribuir a produção, diminuindo assim os custos e seus impactos no final.

\subsection{PROCESSO LOGÍSTICO}

Nas lições de Silva, (2015, p. 5), ao conceituar o processo logístico, aborda que "um processo tem uma logica operacional, da qual fornecem-se produtos e serviços que atendam aos interesses dos consumidores a preços satisfatórios.

Sobre o processo logístico, Silva (2015) explica que é muito importante entender que os processos possuem entradas e saídas bem definidas. As entradas seriam matérias-primas, como borracha, plástico; insumos. Já as saídas são os produtos ou serviços que são gerados, podendo ser uma cadeira, um carro, uma refeição, um atendimento em uma fila de banco. 
O profissional da logística deve-se atentar aos processos logísticos, em razão dos mesmos trabalharem de maneira integrada, necessitando da cooperação de todos para a obtenção da uma eficiência formada na cadeia logística.

Segundo Valle; Oliveira, (2013), é necessário fazer a boa gestão do processo e, essencialmente, acompanhá-lo para garantir que todas as atividades sejam feitas de forma eficiente e que nada saia do padrão.

Isso ocorre porque os processos refletem os fluxos de trabalho diário da empresa. São sequenciamento das etapas ou atividades, transformação de entradas e insumos; agregação de valor, geração de produto ou serviço específicos como saída e atendimento às necessidades de pessoa, clientes, consumidores (VALLE; OLIVEIRA, 2013).

Nesse contexto, Paura (2012), explica que os processos logísticos são todas as ações realizadas dentro de uma empresa para controlar e planejar melhor a logística de um produto.

O processo logístico engloba questões que vão desde a negociação com o fornecedor até a distribuição do produto ao consumidor final, considerando todo o fluxo de materiais e informações incorporados nos processos. (PAURA, 2012)

Inclui também o planejamento, a execução e o controle, nos quais asseguram a integridade e a entrega do produto ao seu cliente. Com o objetivo de otimizar ao máximo uma operação cotidiana da empresa, para que ela possa ser realizada da maneira mais rápida possível.

Portanto, conseguir esta integração é algo extremamente complexo de se implantar, pois além de envolver os sistemas de informações, ainda envolve a cultura dos funcionários da empresa. 


\subsection{ADMINISTRAÇÃO DE MATERIAIS}

A administração de materiais compreende o agrupamento dos materiais de varias origens, e a coordenação dessa atividade com a demanda de produtos ou serviços da empresa.

Desse modo, soma esforços de vários setores, que naturalmente, apresentam visões diferentes.

Segundo Dias (2019), a administração de materiais, poderia incluir a maioria ou a totalidade das atividades realizadas dos seguintes departamentos: Compras, recebimento, planejamento e controle da produção, expedição, transportes e estoques.

Em contrapartida, nos estudos de Pozo, (2017, p. 54), a administração de materiais é o conjunto de atividades que tem por objetivo "planejar, executar e controlar os materiais adquiridos e usados por uma organização com base nas especificações e no uso dos produtos a serem adquiridos por ela."

Todo esse processo deve ser realizado da maneira mais eficiente e econômica possível.

A administração de matérias trata de todas as atividades associadas à aquisição de matérias-primas para o abastecimento das organizações, abrangendo o controle de estoque e a decisão da reposição do mesmo, a escolha de fornecedores, os processos de compra, o armazenamento e a entrega para produção, sincronizando tudo isso com as necessidades de produção (POZO, 2017)

Em relação as principais atividades inerentes à administração de materiais, Corrêa, (2017), explica que com a integração da administração de materiais e distribuição física, o profissional responsável deve administrar o controle e a direção, objetivando suprir as expectativas associadas ao aumento das receitas e vendas. Sendo assim, o mesmo deve elaborar um planejamento, de modo a se organizar, tendo o controle e o comando dos processos das empresas públicas e privadas. 
De acordo com a cultura e as normas estabelecidas na empresa, a elaboração de formas de trabalho, a fim de se alcançar resultados eficientes e eficazes se faz necessário. Deste modo, o processo da administração de materiais exige cuidados para obter êxito no resultado.

Portanto, gerenciar com eficiência e exatidão o movimento de entradas e saídas dos materiais necessários à instituição, é uma atividade complexa e que envolve vários fatores. Por esse motivo, é de extrema importância que a empresa e seus respectivos profissionais busquem conhecimentos teóricos e práticos que os possibilitem desenvolver, de forma eficaz, a administração de materiais.

\subsection{FERRAMENTA 5W2H}

Dado o atual cenário econômico com um mercado altamente competitivo, não ter um planejamento estratégico pode gerar impactos negativos nas suas ações e nos seus processos.

O método da ferramenta $5 \mathrm{~W} 2 \mathrm{H}$, consiste basicamente em fazer perguntas no sentido de obter as informações primordiais que servirão de apoio ao planejamento de uma forma geral.

A planilha $5 \mathrm{~W} 2 \mathrm{H}$ é extremamente útil para empresas que anseiam crescer e realizar bons planejamentos.

Assim, por ser uma ferramenta prática, ela pode ser adotada por diferentes organizações de diferentes portes, em razão da mesma não necessitar de uma equipe técnica especializada, uma vez que tenha alguém que saiba realizar todo o processo, organizando-o de modo a obter muito sucesso.

É um método muito simples usado para agilizar cada processo de uma empresa, ou seja, se "tempo é dinheiro", a planilha 5W2H possibilita a empresa um ganho de capital maior. Assim, vale ressaltar que, em um mercado altamente competitivo, a deficiência do planejamento de ações e processos podem gerar inúmeros prejuízos, bem como a perda de vantagem competitiva. 
Segundo as lições de Possarle (2014, p. 102), "a ferramenta 5W2H pode ser entendida como uma maneira de estruturarmos o pensamento de uma forma bem organizada e materializada antes de implantarmos alguma solução no negócio."

Sobre a temática, os estudos de Pertence e Melleiro (2016), explicam que a ferramenta $5 \mathrm{~W} 2 \mathrm{H}$ é um checklist de determinadas atividades que precisam ser desenvolvidas com o máximo de clareza possível por parte dos colaboradores em um projeto. Ela tem por função, mapear as atividades, onde ficará estabelecido o que será feito, quem fará o quê, em qual período, em qual área da empresa e todos os motivos pelos quais essas atividades devem ser realizadas.

Para Bassan, (2018), a ferramenta 5W2H, é muito útil para as organizações em geral, pois elimina as dúvidas que possam surgir sobre a atividade que será realizada ou o processo que será feito.

Segundo Valle; Oliveira, (2013), o método 5W2H consiste basicamente em fazer perguntas, no sentido de se obter as informações primordiais que servirão de apoio ao planejamento de uma forma geral.

Por fim, ressalta-se que para fazer a planilha $5 \mathrm{~W} 2 \mathrm{H}$ é necessário ter em mente as causas do problema e realizar cada etapa de maneira cuidadosa sempre de forma correta.

\section{MATERIAIS E MÉTODOS}

\subsection{PROCEDIMENTOS METODOLÓGICOS}

O presente item descreverá de forma clara o processo de solução do problema elencado na introdução, citando quais critérios, estratégias e instrumentos foram utilizados, bem com suas formas de uso.

Conforme apontam Cobra (2012, p. 51), "a metodologia quando bem escolhida e adequada ao que se quer obter com a pesquisa, torna os objetivos específicos, aponto de chegarmos a uma conclusão a respeito do que está em estudo." 


\subsubsection{QUANTO A NATUREZA}

O estudo de caso é um tipo de pesquisa que "consiste em coletar e analisar informações sobre determinado indivíduo, uma família, um grupo ou uma comunidade, a fim de estudar aspectos variados de sua vida, de acordo com o assunto da pesquisa" (PRODANOV; FREITAS, 2013, p. 60).

Pode-se desenvolver, a partir de pesquisa qualitativa ou quantitativa. É um estudo compreendido pela investigação de um objeto, de uma unidade de forma aprofundada (PRODANOV; FREITAS, 2013).

\subsubsection{QUANTOS AOS FINS}

Para a realização desta pesquisa a equipe realizou uma entrevista com a Sra. Ituanny Ayka dos Santos da Silva, enfermeira e coordenadora da casa de apoio, onde se mostrou bastante prestativa e acessível ao falar abertamente sobre cada pergunta feita pela equipe.

As perguntas foram bem elaboradas para a entrevistada não ter dúvidas nas respostas quanto aos serviços que a instituição oferece.

Durante a entrevista, a Sra. Ituanny foi bastante objetiva quanto as respostas, algumas ela soube responder, outras ela não soube informar. Mas, de forma geral, as informações fornecidas foram de suma importância para elaboração do relatório.

É oportuno destacar os ensinamentos de Lakatos (2003, p. 201), onde ele ensina que "a entrevista deve terminar como começou, isto é, em ambiente de cordialidade, para que o pesquisador, se necessário possa voltar para obter novos dados."

\subsubsection{QUANTOS AOS MEIOS}

Referente aos meios utilizados, adotamos como procedimento um levantamento bibliográfico, onde foi realizado em um recorte de tempo, fornecendo uma visão geral sobre $o$ assunto abordado nesse projeto. 
Existem, no entanto, pesquisas científicas baseadas somente em pesquisas bibliográficas, nas quais procuram referências teóricas publicadas com o propósito de recolher informações ou conhecimentos prévios sobre um determinado tema, a fim de obter respostas aos questionamentos apresentados. (FONSECA, 2002).

Conforme a pesquisa documental realizada na instituição, através de documentos com objetivo de estudo, foi feito um questionário com vistas a realizar um levantamento quanto aos serviços que a casa de apoio oferece.

Prodanov; Freitas, (2013), conceitua análise documental como coleta de dados, possui vínculo com as informações a serem levantadas, para tomada de decisão da empresa.

Para tal pesquisa, utilizou-se documentos para validação de devidas informações que compreende o mecanismo de funcionamento e estruturação que a instituição Representação de Borba - Casa de Apoio Coração de Mãe, segue como manual sistêmico de suas atividades, facilitando o estudo e compreensão através da pesquisa que auxilia na escolha da ferramenta administrativa ao qual será utilizada para solucionar os pontos fracos que surgem ao longo da análise estrutural da empresa.

\subsection{CARACTERIZAÇÕES DA INSTITUIÇÃO}

A Representação de Borba - Casa de Apoio Coração de Mãe, é uma instituição sem fins lucrativos e tem como objetivo dar o suporte necessário para pacientes e seus acompanhantes naturais do Município de Borba/Am e adjacências (ou seja, comunidades ribeirinhas próximas ao município), que não possuem recursos financeiros e se encontram com problemas de saúde, buscando por tratamentos especializados como ginecologistas, cardiologistas entre outros, na cidade de Manaus.

No que diz respeito a estrutura da casa de apoio para receber os pacientes e seus acompanhantes, a instituição dispõe de cinco quartos, sendo quatro suítes, totalmente 
climatizadas, equipadas com bicamas e armadores de rede, uma sala, uma cozinha e uma lavanderia.

\section{RESULTADOS E DISCUSSÕES}

Com base nos estudos realizados na etapa do diagnóstico organizacional, foi constatado que a instituição em estudo possui pontos fundamentais em cada área funcional da organização, conforme podemos observar abaixo:

Gráfico 1: Análise das áreas funcionais

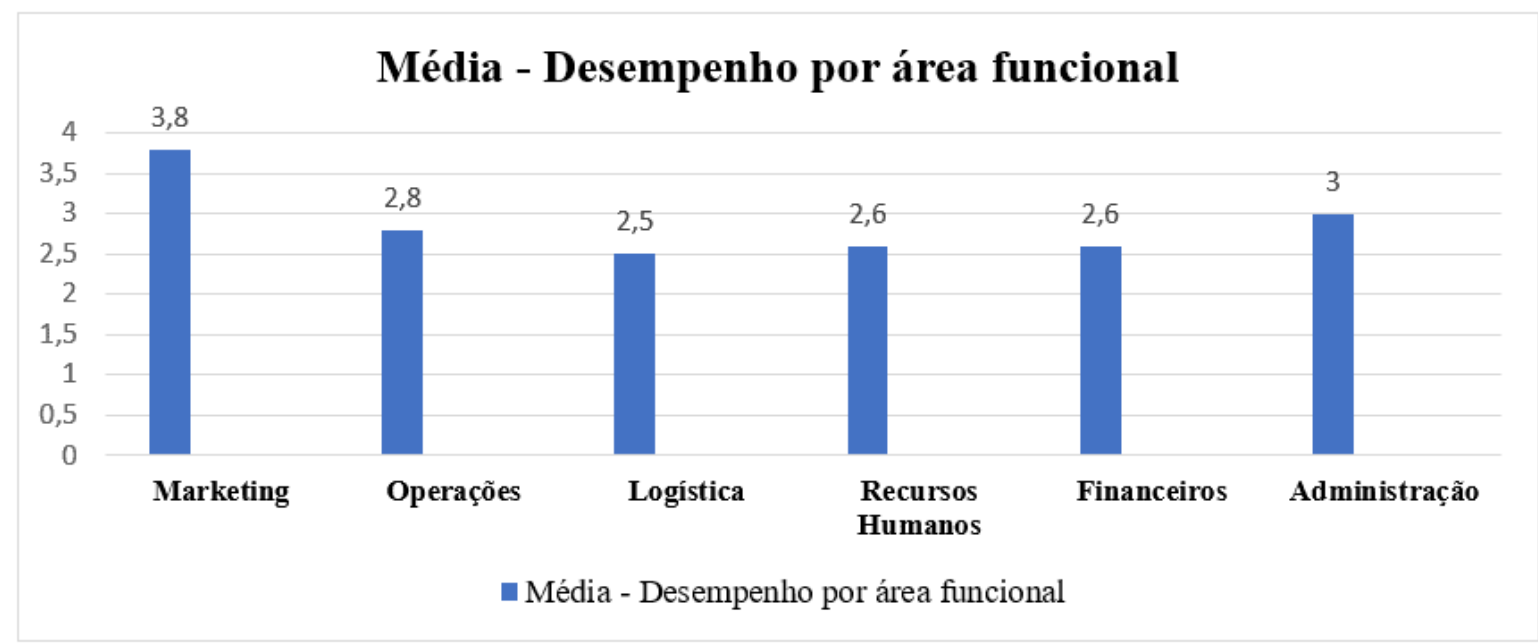

Fonte: Elaborado pelos autores, com base na pesquisa de campo, abril, 2020.

Com base no levantamento de dados, foi constatado que dentro da instituição existem algumas áreas funcionais que apresentam falhas ou que não atendem à demanda com eficiência.

Com base no Gráfico 1, a equipe constatou que apesar da instituição prezar pelo compromisso com os pacientes, o ponto mais crítico detectado se concentra respectivamente na área da logística, pelos seguintes fatores:

A instituição não possui um sistema bem estruturado sobre o controle de entrada e saída dos materiais que são utilizados nos pacientes. 
Os erros encontrados na coordenação da instituição, também podem gerar prejuízos financeiros para a casa de apoio e uma sequência de falhas como falta de material.

A falta de organização propicia questões como desvios, desperdícios e perdas. A instituição tem problemas de comunicação entre outros setores. A instituição faz pouca utilização das ferramentas tecnológicas para divulgar os serviços prestados.

Assim, para conseguir resultados satisfatórios para a instituição e superar a concorrência, é preciso contornar os desafios da cadeia de suprimentos e investir em boas práticas de gestão em logística.

Desse modo, é de suma importância que se estabeleça estratégias para garantir o sucesso da casa de apoio, a instituição não pode negligenciar de forma alguma a gestão no processo logístico.

Quadro 1: Área de logística da instituição

\begin{tabular}{|c|c|c|c|c|c|c|}
\hline \multirow{2}{*}{\multicolumn{2}{|c|}{$\begin{array}{l}\text { ÁREA FUNCIONAL } \\
\text { LOGÍSTICA }\end{array}$}} & \multicolumn{5}{|c|}{ NIVEL OU GRAU DE AVALIAÇÃO } \\
\hline & & \multirow{2}{*}{$\begin{array}{l}\text { Ponto } \\
\text { muito } \\
\text { forte } 5\end{array}$} & \multirow{2}{*}{$\begin{array}{l}\text { Ponto } \\
\text { forte } 4\end{array}$} & \multirow{2}{*}{$\begin{array}{l}\text { Ponto } \\
\text { médio } 3\end{array}$} & \multirow{2}{*}{$\begin{array}{l}\text { Ponto } \\
\text { fraco } 2 \\
x\end{array}$} & \multirow{2}{*}{$\begin{array}{l}\text { Ponto } \\
\text { muito } \\
\text { fraco } 1\end{array}$} \\
\hline 1 & $\begin{array}{l}\text { A instituição possui um } \\
\text { setor específico de } \\
\text { logística }\end{array}$ & & & & & \\
\hline 2 & $\begin{array}{l}\text { A instituição possui um } \\
\text { fluxograma }\end{array}$ & & & & $x$ & \\
\hline 3 & $\begin{array}{l}\text { A instituição possui } \\
\text { armazenamento próprio }\end{array}$ & & & $x$ & & \\
\hline 4 & $\begin{array}{l}\text { Existe controle dos } \\
\text { produtos de consumo }\end{array}$ & & & $x$ & & \\
\hline 5 & $\begin{array}{l}\text { Há rastreamento de } \\
\text { documentos internos }\end{array}$ & & & & $x$ & \\
\hline
\end{tabular}




\begin{tabular}{|c|c|c|c|c|c|c|}
\hline 6 & $\begin{array}{l}\text { Alta rotatividade de } \\
\text { funcionários }\end{array}$ & & & $x$ & & \\
\hline 7 & $\begin{array}{l}\text { Possui profissionais } \\
\text { especializados }\end{array}$ & & & $x$ & & \\
\hline 8 & Altos níveis de estoques & & & & $x$ & \\
\hline 9 & $\begin{array}{l}\text { Há investimentos em } \\
\text { treinamento }\end{array}$ & & & & $x$ & \\
\hline 10 & Parcerias & & & $x$ & & \\
\hline \multicolumn{2}{|c|}{ TOTAL $(\Sigma)$} & 0 & 0 & 1,5 & 1 & 0 \\
\hline \multicolumn{2}{|c|}{$\begin{array}{l}\text { MÉDIA POR GRAU (POR } \\
\text { COLUNA) }\end{array}$} & 0 & 0 & 1,5 & 1,0 & 0 \\
\hline \multicolumn{2}{|c|}{$\begin{array}{l}\text { DESEMPENHO DA ÁREA } \\
(\Sigma) \text { TOTAL }\end{array}$} & \multicolumn{5}{|l|}{2,5} \\
\hline
\end{tabular}

Fonte: Elaborado pelos autores, com base na pesquisa de campo, abril, 2020.

Com base no Quadro 1, a equipe constatou que apesar da instituição prezar pelo compromisso com os pacientes, os pontos mais críticos detectados se concentram respectivamente nos itens de números 3, 4, 6, 7 e 10. Referente aos itens de pontos fracos, destacam-se os itens de números 1, 2, 5, 8 e 9. Conforme podemos observar, esses itens podem ser vistos como um alerta sobre futuros problemas dos quais que podem acabar atrapalhando no desempenho da instituição. Assim, entende-se que o gestor deve identificar e corrigir as possíveis lacunas e falhas logísticas para garantir um atendimento com um nível de qualidade de serviço adequado à demanda.

Logo, é possível entender que a falta de um planejamento logístico pré-definido por parte da casa de apoio faz com que mesma não seja reconhecida no mercado, o que reflete no comportamento do público alvo (os pacientes), que por não conhecer bem a marca, acabam preferindo a casa de apoio dos concorrentes, perdendo assim a oportunidade de crescimento.

Ante o exposto, o diagnóstico proporcionará informações que respondam a seguinte questão: Como a implementação de um planejamento logístico na instituição, poderá 
garantir ações que sejam capazes de gerar bons resultados a curto, médio e longo prazo?

Quadro 2: Ações Interventivas

AÇÕES INTERVENTIVAS

SETOR: Serviço de RESPONSÁVEL: Ituanny Ayka dos Santos da Silva. apoio a logística da

Casa de Apoio Coração

PRAZO: Primeiro semestre de 2021.

de Mãe.

OBJETIVO: Garantir

ações que sejam

capazes de gerar bons

resultados a curto,

médio e longo prazo.

ITEM AÇÃO

PRECEDENTE

TEMPO

CUSTO

INTERVENTIVA

1 Criação de Falta de controle sobre

Mensalmente $\mathrm{R} \$ 7.000,00$

indicadores de a eficiência e eficácia

desempenho. dos serviços prestados.

2 Criar um Falta estabelecer os Primeiro $R \$ 10.000,00$

Planejamento procedimentos, as semestre de

estratégico da etapas e os recursos 2021.

empresa. materiais e humanos

necessários para

funcionamento da

instituição.

3 Investir em novas Falta de controle nos Primeiro $\mathrm{R} \$ 40.000,00$

tecnologias. rastreamentos de semestre de

documentos internos. 2021. 


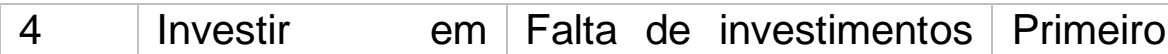
$R \$ 5.000,00$
Programas de em treinamento para semestre de
Treinamento e melhorar as atividades 2021.
Desenvolvimento. logísticas na empresa.

Fonte: Elaborado pelos autores, com base na pesquisa de campo, abril, 2020.

Como desdobramento do plano de ação, são sugeridas ações de melhorias para todo o processo pesquisado, incorporados nos seguintes temas: Criação de indicadores de desempenho; Criação de um planejamento estratégico da instituição; investir em novas tecnologias; e investir em programas de treinamento e desenvolvimento.

\subsection{CRIAÇÃO DE INDICADORES DE DESEMPENHO}

O ponto principal para a criação de indicadores de desempenho logísticos é focar na responsabilidade da conservação e controle de medicamentos no estoque da instituição.

Como eles são o "produto" do setor, o resultado desses pontos demonstra a eficiência logística da organização. Dessa forma, ao se basear nesse fator, a instituição estudada poderá definir os indicadores de desempenho mais relevantes para acompanhar seus resultados, sempre considerando a estratégia adotada, se a ideia é focar no crescimento de acolhimento aos pacientes na instituição.

Quadro 3: 5w2h - Criação de indicadores de desempenho

Criação de indicadores de desempenho

O que? Estabelecer os procedimentos, as etapas e os recursos materiais e humanos necessários para funcionamento.

Por quê? Para monitorar o controle sobre a eficiência e eficácia dos serviços prestados através de tabelas e fluxogramas.

Onde? Ferramenta de Excel. 
Quando? Mensalmente.

Quem? Gerente de Produção.

Como? Criação de planilha de monitoramento eletrônico.

Quanto? R\$7.000,00

Fonte: Elaborado pelos autores, com base na pesquisa de campo, abril, 2020.

\subsection{CRIAÇÃo DE UM PLANEJAMENTO ESTRATÉGICO DA INSTITUIÇÃO}

A reestruturação da empresa nasce com elaboração de seu planejamento estratégico. Para tanto, a instituição do estudo de caso necessita de consultoria para desenvolvimento do plano com a preparação do processo. O planejamento estratégico da empresa é o processo pelo qual a administração tenta definir os cenários futuros de uma instituição e entender qual será o plano de ação para que os objetivos sejam alcançados.

Planejar estrategicamente, então, significa equilibrar as oportunidades encontradas nos ambientes interno e externo para alcançar os objetivos futuros. É assim que a instituição 'Casa de Apoio Coração de Mãe', alcançará o sucesso e, mesmo diante do cenário de crise econômica e pandemia, reduzirá os efeitos dela.

Como sugerido no quadro 4, a instituição pode através do planejamento, buscar especialistas, a fim dos mesmos definirem suas estratégias e planos, visão, diagnóstico estratégico, missão e políticas, objetivos e metas.

Bem como, realizar suas pesquisas de ambiente e oportunidade de mercado e, ainda definir seus indicadores, como exemplo ter mais controle sobre as atividades que são realizadas na instituição.

Quadro 4: 5w2h - Criação de Planejamento Estratégico da instituição

Criação de Planejamento Estratégico da empresa 

O que? Estabelecer os procedimentos, as etapas e os recursos materiais e humanos necessários para funcionamento.
Por quê? Realizar diagnóstico e análise de oportunidades no mercado.
Onde? Consultores do SEBRAE ou contratar empresas de consultorias.
Quando? Primeiro semestre de 2021.
Quem? Responsável pela empresa.
Como? Contratação da consultoria para determinar 0 processo do planejamento estratégico da empresa - Estabelecer os procedimentos, as etapas e os recursos materiais e humanos necessários para funcionamento.

Quanto? $R \$ 10.000,00$.

Fonte: Elaborado pelos autores, com base na pesquisa de campo, abril, 2020.

\subsection{INVESTIR EM NOVAS TECNOLOGIAS}

A instituição do estudo de caso, com base na análise tem urgência em investir em tecnologia, no que se na atualização eventual dos itens de informática, como computadores e softwares.

Para a empresa que pretende se reestruturar e se tornar referência no acolhimento e atendimento de famílias, é importante a incorporação de tecnologia de sistemas agregados às redes sociais, campanhas de impulsionamento, e-commerce e afins.

É oportuno ressaltar que independente do porte da empresa, dos tipos de produto e das operações, a tecnologia facilita o desenvolvimento de técnicas para transformar insumos em produtos gerando resultados para a instituição.

Dela, depende quase tudo, pois determina o processo de produção, fluxo de materiais, métodos e técnicas de trabalho e equipamentos.

Quadro 5: 5w2h - Investir em novas tecnologias 
O que? Investir em novas tecnologias para aumentar os níveis de serviços proporcionados aos pacientes.

Por quê? Quase tudo depende de tecnologia: determina o processo de produção, fluxo de materiais, métodos e técnicas de trabalho, máquinas e equipamentos.

Onde? $\quad \mathrm{Na}$ instituição.

Quando? Primeiro semestre de 2021.

Quem? Responsável pela instituição com equipe de Design.

Como? A partir do plano estratégico, com especialistas adquirir e manter atualizados computadores e softwares.

Quanto? $R \$ 40.000,00$.

Fonte: Elaborado pelos autores, com base na pesquisa de campo, abril, 2020.

\subsection{INVESTIR EM PROGRAMAS DE TREINAMENTO E DESENVOLVIMENTO}

A observação que se faz à instituição é que os profissionais contratados sejam treinados continuamente e suas necessidades de treinamento apontadas anualmente. Além dos treinamentos individuais, promover regularmente capacitações em outras áreas da instituição, principalmente para área de logística.

Assim, a seleção de pessoas voltadas ao setor de criação deve ser realizada por um profissional com capacidade técnica para avaliar o potencial do candidato e decidir com sabedoria as suas escolhas. Em razão da empresa exigir a mínima qualidade e criatividade de seus produtos.

Com o treinamento de funcionários, é possível desenvolver as habilidades e potencialidades de cada um e, como consequência, gerar o desenvolvimento da própria instituição. Um dos motivos para investir na capacitação dos colaboradores é a melhoria na produtividade da instituição. Quando treinados de maneira correta, os profissionais adquirem ou aperfeiçoam habilidades que são fundamentais para seu exercer o seu trabalho. 
Ressalta-se que uma equipe de profissionais bem treinados e eficientes eleva o nível de qualidade dos serviços e produtos oferecidos pela instituição.

Quadro 7: 5w2h - Investir em programas de treinamento e desenvolvimento

Investir em programas de treinamento e desenvolvimento

O que? Permite que o colaborador cresça intelectualmente e profissionalmente dentro da instituição.

Por quê? Para juntos melhorar as atividades logísticas na instituição.

Onde? Através de cursos no SENAC, consultores SEBRAE ou contratar empresas de consultorias.

Quando? Primeiro semestre de 2021.

Quem? Profissional na área de $\mathrm{RH}$ e empresa terceirizada.

Como? Contratação da consultoria para determinar o processo de programas de treinamento e desenvolvimento.

Quanto? R\$5.000,00.

Fonte: Elaborado pelos autores, com base na pesquisa de campo, abril, 2020.

\section{CONSIDERAÇÕES FINAIS}

A proposta para a realização deste estudo de caso, deu-se a partir do diagnóstico organizacional, realizado junto à Instituição de Borba - Casa de Apoio Coração de Mãe.

Para tanto, desenvolveu-se uma pesquisa com aplicação de entrevista com perguntas pré-definidas, in loco, que nos permitiu enxergar de forma clara as deficiências e falhas na logística da instituição, dentre os quais, destacam-se: "a falta de um setor específico de logística; a instituição não realizar fluxogramas; não fazer um rastreamento de documentos internos; ter um alto nível de estoques e não ter investimentos em treinamento."

Neste sentido, é de suma importância perceber quais são as fraquezas e forças da instituição, quais as possibilidades de crescimento e desenvolvimento e com esses 
resultados em mãos investir em um planejamento de logística que seja adequado e que visualize o público-alvo, mediante o foco estabelecido.

Assim, buscando apresentar estratégias e soluções viáveis de acordo com a necessidade e realidade logística que a instituição se encontra atualmente, sugeriuse a utilização da ferramenta $5 \mathrm{~W} 2 \mathrm{H}$, como forma de melhoria contínua, para executar planos de ações para os problemas e assim, atingir o objetivo principal do estudo que é direcionar as atividades como forma de maximizar os resultados operacionais da casa de apoio.

Em razão das limitações de tempo sobre o presente estudo, alguns questionamento serão deixados em abertos, dentre estes a verificação da eficácia da ferramenta em todos os itens indicados como sugestões para a empresa.

Sugere-se para estudos futuros avaliar os resultados obtidos com o uso da ferramenta $5 \mathrm{~W} 2 \mathrm{H}$, em todos os processos da instituição do estudo de caso.

A pesquisa concebeu expressiva importância para os acadêmicos e para a instituição. Proporcionou aos acadêmicos a experiência prática, baseada nos ensinamentos e teorias doutrinados no curso. Assim como, proporcionou a instituição estudada, informações precisas baseada na pesquisa aplicada, na qual a empresa pode avaliar a sua atuação, pontuar pontos fortes e fracos, podendo assim superar-se em seus processos.

\section{REFERÊNCIAS}

BASSAN, Edilberto José. Gestão da Qualidade: Ferramentas, Técnicas e Métodos / Edilberto José Bassan. 1르 edição - Curitiba, Pr. 2018. 153p.

CASTIGLIONI, José Antônio de Mattos - JUNIOR, Romualdo Francisco Minetto. Processos Logísticos - Série Eixos - Gestão e Negócios. Editora: Érica, 2014.

CHIAVENATO, Idalberto. Introdução a Teoria da Administração. Associação Brasileira de Direitos Reprográficos. 9ª Edição, Manole Ltda., 2014. 
CORRÊA, Henrique L. Administração de Produção e Operações: Manufatura e serviços, uma abordagem estratégica / Henrique L. Corrêa, Carlos A. Corrêa. 4a Ed. São Paulo: Atlas, 2017.

DIAS, Marco Aurélio P. Administração de materiais: Uma abordagem logística/ Marco Aurélio P. Dias. 7ª Ed. São Paulo: Atlas, 2019.

FONSECA, J. J. S. Metodologia da pesquisa científica. Fortaleza: UEC, 2002. Apostila.

LAKATOS, Eva Maria. Fundamentos de metodologia científica / Marina de Andrade Marconi, Eva Maria Lakatos. - 5. ed. - São Paulo: Atlas 2003.

MARQUES, Cícero Fernandes; ODA, Érico. Atividades Técnicas na Operação Logística. Cícero Fernandes Marques; Érico Oda. Curitiba: IESDE Brasil S.A., 2012. $196 \mathrm{p}$.

MATTOS, C. L. G. at al. (Org.) Pesquisas em Educação: a produção do Núcleo em Etnografia e Educação (NetEDU). [Livro Eletrônico] Campina Grande: Realize, 2015, $358 p$.

PAURA, Glávio Leal. Fundamentos da Logística. Curitiba-PR, 2012. Disponível em: <http://redeetec.mec.gov.br/images/stories/pdf/proeja/fundamentos_logistica.pdf> Acesso em: 10 set. 2020.

PERTENCE, Poliana Prioste; MELLEIRO, Marta Maria. Implantação de ferramenta de gestão de qualidade em Hospital Universitário. Rev. esc. enferm. USP, São Paulo, v. 44, n. 4, p. 1024-1031, Dec. 2010. Disponível em: <http://www.scielo.br/scielo.php?script=sci_arttext\&pid=S008062342010000400024\& lng=en\&nrm=iso $>$. Acesso em: 08 out. 2020. https://doi.org/10.1590/S008062342010000400024.

POSSARLE, Roberto. Gestão: Ferramentas da qualidade. 1. Ed. São Paulo: SENAISP, 2014. 
POZO, Hamilton. Administração de Recursos Materiais e Patrimoniais: Uma abordagem logística/ Hamilton Pozo. - 7ª̣ Ed. São Paulo: Atlas, 2017.

PRODANOV, Cleber Cristiano; FREITAS, Ernani Cesar de. Metodologia do trabalho científico: métodos e técnicas da pesquisa e do trabalho acadêmico. 2. ed. Novo Hamburgo: Feevale, 2013.

RIBEIRO, Antônio de Lima. Teorias da Administração. 3ª Ed. Saraiva, 2016.

ROCHA, Rudimar Antunes da. Administração de Marketing / Rudimar Antunes da Rocha e Allan Augusto Platt. - 3르 Ed. - Florianópolis: Departamento de Ciências da Administração/UFSC, 2015.

SANTOS, Lorena. Revisão Bibliográfica: um recurso para melhorar o seu negócio. Editora Poison. 3(2): 4-15. 2018. Disponível em: <https://formulajr.com.br/revisao-bibliografica/> Acesso em: 12 out. 2020.

SILVA, Leandro Costa da. Gestão e Melhoria de Processos - Conceitos, Técnicas e Ferramentas. Ebook Kindle. São Paulo, 2015.

VALLE, R.; OLIVEIRA, S. B. Análise e modelagem de processos de negócio: foco da notação BPMN (Business Process Modeling Notation). São Paulo: Atlas

Enviado: Outubro, 2020.

Aprovado: Novembro, 2020. 